\title{
High Sensing
}

National Cancer Institute

\section{Source}

National Cancer Institute. High Sensing. NCI Thesaurus. Code C63121.

Problem associated with the amount of input required by the device to detect a signal being higher than expected/desired. 